\title{
La mirada del flâneur en el cine de la nouvelle vague
}

\section{The gaze of the flâneur in the cinema of the nouvelle vague}

\author{
RAFAel Gómez AlONSO \\ Universidad Rey Juan Carlos \\ rafael.gomez@urjc.es
}

Recibido: 11/09/2019

Aceptado: 18/10/2019

\section{Resumen}

El presente texto trata de ofrecer una aproximación a la visión fílmica de la experiencia del paseante urbano frente a la ciudad que transita. Para ello se analizarán una serie de fragmentos de películas, englobadas dentro de la corriente de la nouvelle vague francesa, atendiendo a los modos de contemplación de la ciudad por diversos directores cinematográficos y a la creación de una estética particular como seña o marca de autor. Con esta investigación se pretende entender cómo es el tránsito de la ciudad como proceso discursivo, poético, contemplativo e interactivo. También se trata de entender el modelo de representación y focalización que utilizan diferentes realizadores ante su visión de la ciudad.

\section{Palabras clave}

Flanêur. Experiencia Estética. Nouvelle Vague. Ciudad. Representación Visual.

\begin{abstract}
The present text tries to offer an approach to the filmic vision of the experience of the urban walker in front of the city that transits. For this, a series of fragments of films, encompassed within the French nouvelle vague stream, will be analyzed, taking into account the ways of contemplation of the city by various cinematographic directors and the creation of a particular aesthetic as a sign or author's mark. This research aims to understand how the city transit is as a discursive, poetic, contemplative and interactive process. It is also about understanding the representation and targeting model that different filmmakers use before their vision of the city.
\end{abstract}

\section{Keywords}

Flanêur. Aesthetic Experience. Nouvelle Vague. City. Visual Representation. 
Referencia normalizada: GÓMEZ ALONSO, RAFAEL (2019): "La mirada del flâneur en el cine de la nouvelle vague". En Arte y Ciudad. Revista de Investigación, no 15-16 (2019), págs. 37-50. Madrid. Grupo de Investigación Arte, Arquitectura y Comunicación en la Ciudad Contemporánea, Universidad Complutense de Madrid.

Sumario: 1. Introducción contextual y metodológica. 2. La mirada del flâneur. 3. Antecedentes sociológicos. 4. El flâneur en la nouvelle vague. 5. Conclusiones. 6. Bibliografía.

\section{Introducción contextual y metodológica.}

El flâneur ha sido definido, en líneas generales, como el paseante que deambula sin rumbo, callejea y percibe la ciudad como experiencia estética. Las sensaciones que se producen o reflejan en dicha experiencia pueden ser positivas, negativas, atractivas, ensoñadoras, metafóricas, eidéticas (relacionadas con un pasado), fáticas, extrañas, desconocidas o abarcar todo de tipo de cualidades psicosociales y comunicativas que determinen su conexión con el entorno.

A veces, el dejarse llevar por la imprevisibilidad y la casualidad en la elección del recorrido dicta el sentido de la experiencia. Es, por tanto, el azar e indeterminación de lo que se observa una de las cualidades esenciales del flâneur, aunque dicha trayectoria se haya previsto ante la meta de un objetivo. Así por ejemplo, una persona puede pasear mientras va de camino a su trabajo pero el tránsito puede variar en función de lo que observe manifestando un determinado placer estético hacia un objeto o manifestación que surja en dicho itinerario. En este sentido, lo previsible se puede tornar en imprevisible por la focalización que se obtenga. El pasear o deambular por la ciudad es, por tanto, una actividad que afecta a los sentidos y constituye una función estética (Thoreau, 2006).

Durante los años sesenta del pasado siglo XX comienzan a emerger las determinadas corrientes cinematográficas enmarcadas dentro de lo que se vino a denominar, bajo un común denominador, como nueva ola, en la que se establecía una concepción cinematográfica basada en una ruptura de representación del lenguaje clásico apostando por un desarrollo más personal con una condición de autoría fuertemente acentuada. Dicha corriente se vino a deno- 
minar en el territorio francés como nouvelle vague o nueva ola francesa, y estuvo amparada por la canonización de un estilo fílmico designado como política de los autores (De Baecque, 2003) en la que sus películas tomaban una visión diferente a las propuestas en la narrativa clásica para experimentar la sociedad bajo un prisma de lo que venía a sintetizar el proyecto de posmodernidad. La ruptura creada por estas cinematografías no solo se evidenciaba desde un posicionamiento formalista y de la concepción del lenguaje sino de un modo de pensamiento visual. Tanto directores como protagonistas ejercieron un papel singular, amparados en la filosofía existencialista heredada de la filosofía de Sartre. El posicionamiento que se ejerce tanto en la puesta en escena como en el discurso establecido se considera como una propuesta fílmica que explora la condición de ensayo visual.

Partiendo del modelo de observación que genera la cámara en diferentes directores cinematográficos de la corriente de la nueva ola francesa, el siguiente texto trata de establecer los criterios que rigen la mirada del paseante urbano en el contexto fílmico en relación a sus modos ver, es decir, a su focalización en el acto de pasear. Dicho acto genera una experiencia basada en la indagación del espacio, en las trayectorias marcadas o descubiertas, en las sensaciones de recuerdo a modo de déjà vu, en las ensoñaciones y deseos, y en el surgimiento de una memoria que conecta con otros espacios a modo cronotopos, o conexiones con otros ámbitos y lugares.

En dichas representaciones cinematográficas también coexiste un fenómeno particular que enlaza con el estilo propio del citado movimiento fílmico que es el del dandy, es decir, un flâneur que pasea pero que le gusta ser visto y que le gusta mostrarse a los que se cruzan en su camino. Por tanto la posición y el posicionamiento del individuo toman un lugar importante a la hora de conectar con la experiencia urbana en la experiencia de conocer o descubrir ámbitos nuevos sino de ser descubiertos o reconocidos.

El proceso de investigación utilizado para realizar esta investigación se ha basado en el análisis de la representación audiovisual de pequeños fragmentos de obras fílmicas, lo que se reconoce como ejercicio de microanálisis (Zunzunegui, 1996). Mediante el análisis fílmico de representación visual se estudian diversas perspectivas que atañen a la percepción y experiencia que ejercen determinados personajes, o bien al posicionamiento que ocupa la cámara 
cinematográfica, así como a la relación que se establece con el ámbito circundante; en este caso con el espacio que rodea la metrópoli. Este modelo de análisis de representación se ampara en un doble posicionamiento de cámara subjetiva (la que adopta la visión del actante que mira lo que le rodea) frente a cámara objetiva (la que acompaña al personaje y rodea su espacio creando un mayor distanciamiento).

El análisis de los textos visuales propuesto servirá, a su vez, para aplicar las teorías que subyacen en relatos literarios, sociológicos y filosóficos esbozados por Poe, Baudelaire, Zola, Simmel, Kracauer o Benjamin, entre otros, en torno al paseante decimonónico, ya que constituyen un marco teórico de reflexión de la mirada para adaptarse a la experiencia recreada en este modelo de representación cinematográfica. Por otra parte, se tomarán también como variables de aplicación al análisis visual, las reflexiones antropólógicas enmarcadas dentro de los estudios visuales y culturales contemporáneos desarrollados entre otros por Susan Buck-Morss o Manuel Delgado. Partiendo de estas bases se planteará una exposición centrada en nuevas formas de entender la observación de la metrópolis sustentada desde diferentes modelos de representar al flâneur a través de una serie de directores cinematográficos del estilo escogido, como casos de estudio particulares y complementarios entre sí.

Respecto a la creación de experiencia estética como elemento de reflexión dentro del proceso de la focalización cinematográfica, debe señalarse el papel que cumple la mirada del protagonista frente al espacio, su proyección frente a lo que le rodea a través de determinados estados de ánimo y pasiones que experimenta en determinados lugares. En este proceso intervienen, por tanto, una serie de variables que constituyen la relación de los personajes con su entorno que atañen a cuestiones emotivas, cognoscitivas y volitivas (Schaeffer, 2018), es decir, a sus modos de actuar frente al espacio que les rodea.

\section{La mirada del flâneur.}

La idea del paseante observador que aparece en las grandes ciudades a mediados del siglo XIX fue estudiado por diferentes autores literarios como Edgar Allan Poe, Charles Baudelaire, Honoré de Balzac, Zola o Pío Baroja, mediante diferentes relatos en los que también se exponía el placer estético que surgía en la nueva sociedad de consumo. Posteriormente, durante el primer tercio del siglo XX, aparecen los primeros fundamentos sociológicos de la 
visión de la ciudad metropolitana de la mano de Walter Benjamin, Georg Simmel, Louis Huart o Sigfried Kracauer, entre otros, cuyas teorías han servido de base para formular ensayos sobre la observación de la ciudad, la atención y los regímenes de miradas. Ideas que a finales del siglo XX serán retomadas como base de los denominados estudios visuales encargados de analizar a través de una teoría social cómo se determina un hecho visible, quién y cómo se observa, y de qué forma la visión, el conocimiento y el poder (en tanto que ostentación de la mirada) están estrechamente relacionados.

Tal como expone el antropólogo Manuel Delgado (2006), el espacio urbano expresa un sistema de relaciones sociales cuyos protagonistas interpretan las formas de los escenarios donde conviven. La vida urbana genera actividad y retroalimentación entre los edificios y sus transeúntes, a la vez que cierto extrañamiento ante el continuo cambio y transiciones a que se ve expuesta la ciudad, tanto en sus elementos arquitectónicos como ambientales. El espacio metropolitano genera un sistema dialéctico que responde a la intersección entre percepciones, miradas y representaciones. El dispositivo que afecta al habitante, visitante o paseante de la ciudad radica en el régimen de su mirada hacia lo que observa.

En el deambular del flâneur no interesa solo lo que observa el individuo sino cómo observa, es decir, cómo se representa el acto de su mirada, de su atención, de su fijación y de la posible huella que deja dentro del relato fílmico. A la hora de investigar la percepción urbana se obtienen claves para comprender la cotidianeidad de la ciudad, así como la configuración de las experiencias que adquieren los transeúntes. La significación cambia por los modos de visión y atención que el espectador percibe ante los signos convencionales que aparecen en los espacios de ocio y consumo. A su vez, el conocimiento externo depende del sentido que le ofrezcan los individuos que aparecen en escena.

\section{Antecedentes sociológicos.}

Los textos que exponen los planteamientos del paseante o flanêur reflexionan sobre las experiencias del lugar como ámbito para deambular, la experiencia de pasear, de contemplar la multitud, la mirada curiosa, la ociosidad, el paseante que deambula sin rumbo. A lo largo de la historia, desde que comienzan a establecerse los primeros enclaves metropolitanos, se han escrito diversos relatos y ensayos que, directa e indirectamente, han tratado el tema del flanêur como eje de los discursos. 
Posiblemente una de las obras más enriquecedoras al respecto, que expone las características del paseante urbano, sea el Libro de los Pasajes de Walter Benjamin. En este conjunto de ensayos escritos esencialmente entre 1935 y 1939 se desarrolla, a modo de gran esbozo enciclopédico y estructurado en forma de bricolaje textual de piezas inacabadas, un amplio dossier sociológico de la experiencia urbana del autor atendiendo a las transformaciones sociales y culturales que ocurren en el París urbano durante el siglo XIX. Para ello se atiende a diferentes particularidades de la transformación de la ciudad como modelo de capital social y cultural, destacando sus reflexiones sobre el papel de los grandes almacenes como templo de mercancías, los panoramas, la fotografía, la prostitución, la decoración, los pasajes, las exposiciones universales, la moda, la arquitectura, la pintura, las calles, el coleccionismo, la publicidad, etc. De este modo, a través de la impresión particular como observador de los acontecimientos sociales que surgen en la ciudad se establece una fisonomía urbana a modo de esbozo poliédrico en el que se entrecruzan descripciones frente a citas literarias y ensayísticas, que permiten reflexionar sobre los aconteceres de la metrópolis y sus transformaciones. En diversos escritos de los pasajes se puede vislumbrar cómo la calle es entendida como un hervidero donde se concentra la masa, a la vez que un lugar de extrañamiento y contemplación de las personas.

En dicho texto de Walter Benjamin aparecen diversas referencias a otros autores que también escriben y reflexionan sobre la experiencia del tránsito urbano, como el caso del célebre escritor Baudelaire y sus ensayos sobre El pintor de la vida moderna, que engloban diversos artículos aparecidos en las publicaciones Le Figaro y L'Art romantique en 1863 y 1868 respectivamente. Las reflexiones que surgen de estos textos aportan cuestiones relacionadas con la moda, la belleza, el observador como paseante, el papel del filósofo como analista social o el dandy, persona muy relacionada con el mundo del flanêur que volverá a retomar el cine de la nouvelle vague. En uno de esos artículos que forman parte de la citada obra titulado "El artista, hombre de mundo, hombre de la multitud y niño", se comenta el caso de un título emblemático, que aporta la visión del flâneur decimonónico, denominado El hombre de la multitud y escrito por el célebre novelista de relatos de misterio y terror Edgar Allan Poe en 1840. A esta pequeña narración con tintes sociológicos se la considera como uno de los primeros relatos ejemplares de la percepción de los 
cambios urbanos que surgen en las ciudades recorridas por multitud de personas (en este caso percibidas por el protagonista desde el escaparate de un café en el que se encuentra sentado observando pasar la muchedumbre por las calles y tomando la posición de un antropólogo urbano). Si bien es cierto que otros escritores como Charles Dickens también aportan visiones personales de la percepción de la metrópolis y su transformación industrial, como el caso de sus artículos publicados entre 1834 y 1835 englobados en la obra Escenas de la vida de Londres por "Boz".

Émile Zola, desde una posición naturalista, describió también la recepción del ocio en la ciudad y la figura del dandy (al igual que lo hiciera también Oscar Wilde) como prototipo de personaje seductor configurado bajo un prisma de tedio pero acorde con las transformaciones que otorga la modernidad metropolitana. Dentro de sus obras costumbristas de índole político social que conforman el ciclo novelístico "Les Rougon-Macquart" destaca El paraíso de las damas ${ }^{1}$, publicada en 1883, en la que se describe la mutación de las pequeñas tiendas por los nuevos grandes almacenes, así como la génesis de nuevos ámbitos para observar los productos mientras se pasea por los espacios de estos edificios de consumo material (compra de los productos) o visual (observación de los productos). De este modo asocia la idea de progreso con la explosión de la sociedad de consumo. También algunas de sus novelas como Roma o El vientre de París, relatan de un modo de ensayo antropológico la visión que se percibe al deambular estas ciudades. Muchos de estos espacios serían a su vez fotografiados por el escritor y hoy en día se consideran un legado visual del contexto de la época.

El trabajo del pensador alemán Sigfried Kracauer es de interés respecto a la percepción de la metrópolis y la vida social como paradigma de la modernidad. En sus ensayos, publicados en diferentes revistas entre los años 20 y 30 del pasado siglo XX que engloban su obra La estética sin territorio, expone, entre otras cuestiones, las reacciones del culto de la distracción, el aburrimiento de los transeúntes de la ciudad, los espectáculos de publicidad luminosa, el

\footnotetext{
${ }^{1}$ Existe una versión cinematográfica de la novela con el mismo título, dirigida por Julien Duvivier en 1930 en la que se puede observar desde la representación visual el poder que ejercen los grandes almacenes a finales del siglo XIX. El mismo director filmó un cortometraje documental por la misma época titulado El vientre de los almacenes que sirvió como esbozo para el desarrollo del largometraje.
} 
ornamento de la masa, el poder de la fotografía y la recepción de los relatos cinematográficos, además de hacer reflexiones a las contribuciones del pensamiento de Walter Benjamin, Georg Simmel, Franz Kafka, Dostoievski o Nietzsche.

En 1903 el sociólogo alemán Georg Simmel publica el ensayo La metrópolis y la vida mental en el que describe cómo la eclosión de la vida metropolitana cambia la percepción de la actividad visual. Se metaforiza, de este modo, la intensificación de la estimulación nerviosa como resultado de la rapidez del cambio asociado al nerviosismo urbano. Este tipo de dinamización óptica, que ampara la modernidad de la ciudad, es equiparable al nacimiento del nuevo receptor que surge con la llegada del cinematógrafo a finales del siglo XIX, así como a otras diversiones visuales que forman parte de los que algunos autores han denominado cine de atracciones; tal es el caso de Tom Gunning (1989).

También parece importante destacar cómo en la España del siglo XIX numerosos escritores expusieron reflexiones sobre la ciudad y sus condiciones metropolitanas en sus relatos; así Mariano José de Larra en sus críticas sobre los espectáculos y diversiones llega a reflexionar sobre cómo los habitantes de Madrid en sus paseos salen a ver y ser vistos; por otro lado, algunos relatos de Benito Pérez Galdós describen la situación social de la ciudad bajo una posición de paseante urbano (por ejemplo en Bodas Reales, novela perteneciente a Los Episodios Nacionales). Incluso los denominados escritores costumbristas no dejan de ser descriptores de los ambientes urbanos como Mesonero Romanos con sus Escenas matritenses o Pedro Felipe Monlau (uno de los introductores, a su vez, del daguerrotipo ${ }^{2}$ en España) con la redacción de diversas guías de forastero para conocer ciudades, como el caso de Madrid en la mano. Relatos, todos ellos que de una u otra forma testifican las vivencias personales ante la percepción visual de la ciudad y surgidas como experiencias de flâneur costumbrista. A finales del siglo XIX y principios del XX la labor de

\footnotetext{
${ }^{2}$ Desde sus orígenes, la fotografía servirá como reflejo de la cotidianeidad y la prensa del momento recurrirá a la inclusión de imágenes fotográficas y fotograbados como instrumento para contribuir a las narraciones costumbristas que aparecen redactadas en diversas publicaciones periódicas como el Museo de las familias, el Siglo Pintoresco, el Panorama matritense o el Semanario Pintoresco Español, entre otros. Sobre el papel del realismo icónico y el costumbrismo en España puede consultarse la obra de Lee Fontanella (1982): La imprenta y las letras en la España romántica. Peter Lang Publishers. Berne.
} 
Pío Baroja como narrador de las calles siniestras configura un amplio abanico de su visión poliédrica y subterránea de diversas ciudades (Rocha, 2019).

\section{El flâneur en la nouvelle vague.}

La visión del paseante en el cine permite plantearse cómo se concibe la contemplación de los espacios y habitantes de la ciudad por parte de los personajes y por parte del objetivo cinematográfico; de este modo queda manifestada la curiosidad que denotan los objetos y formas de los edificios, dirigiendo la mirada del receptor hacia nuevos significados adquiridos en la experiencia estética que registra la narrativa fílmica. En este sentido, las películas suponen un proceso de relación con el espacio percibido, con el espacio practicado, con el espacio soñado, con el espacio vivido y con el espacio usado.

Durante la época de la nouvelle vague francesa varios directores se sintieron atraídos por mostrar las relaciones de los personajes con la ciudad. Sus experiencias, ambiciones e impresiones se ven manifestadas de manera directa e indirecta hacia los ámbitos que adoptan una visión particular para desarrollar las acciones de sus protagonistas (cafeterías, lugares de fiesta, grandes avenidas que se recorren en coche o andando pero con una intención de dejarse ver, de disfrutar del paisaje urbano). Por ejemplo, en algunas películas de Jean-Luc Godard se puede percibir la figura del dandy flanêur adaptándolo a situaciones límites del contexto urbano, como en el caso de Jean Paul Belmondo en la película Al final de la escapada, realizada en 1960, donde se observa el vagar por la ciudad atendiendo al cruce de miradas entre lo que se supone el dejarse ver como acto de seducción y el observar cómo se es mirado; o en el caso de la seducción de las figuras femeninas tratadas en un sentido de modelos con inquietudes existencialistas, ejemplificado por Anna Karina en películas como Vivir su vida, dirigida en 1962, en la que se percibe como la actriz percibe la rutina de la ciudad a la vez que es consciente de que es filmada por una cámara, lo que hace partícipe al realizador y espectador del contexto de una flâneur que experimenta su cotidianeidad.

Por otro lado, en algunos filmes de Éric Rohmer el realizador se siente más interesado por la ciudad como fenómeno que predispone la condición del personaje que por sus protagonistas en sí mismos, es decir, es el espacio el que va cobrando cierta notoriedad de dimensión narrativa ante los personajes y el que propone los universos particulares de los individuos. La ciudad es el entorno 
que puede acoger a los personajes ofreciéndoles felicidad o destruyéndoles. Así por ejemplo en el caso del largometraje El signo del león, realizado en 1959, el protagonista se encuentra sumido en la desesperación tras saber que la fortuna que iba a heredar no le corresponde, y el dinero que ha pedido prestado para celebrar su condición de heredero millonario debe pagarlo sin saber cómo poder devolverlo. La frustración ante la soledad en la que se encuentra por el desplazamiento de sus amistades, que ya no confían en él, la incapacidad para encontrar trabajo y la desesperación por no poder llevar una condición de vida determinada (propia del dandy) lleva al personaje a posicionarse a una condición de personaje vagabundo. Lo más interesante de esta película es observar cómo la figura de este arquetipo que pasea seducido por la ciudad comienza a destruirse lentamente cuando comienza a observar que no se resuelven sus objetivos. El paseo como algo agradable comienza a convertirse en algo insoportable. El protagonista maldice la ciudad (continuamente susurra "porquería de París"). El deambular como placer estético hacia la búsqueda de ciertos objetivos que le pueden ayudar a salir de sus problemas se transfiere en un paseo sin rumbo fijo, que llega a culminar en el arrastramiento más miserable al que puede llegar la condición humana. La ciudad transitada y practicada se convierte en un espacio de desesperación, agobio y frontera de la que no hay escapatoria o solución y en la que sólo se puede mostrar rencor. En esta película parece pertinente comprobar la relación y mutación de experiencia estética que pueden desempeñar los espacios urbanos ante la actitud psicológica de los personajes.

Bajo un prisma positivo y opuesto al anterior caso, en el cortometraje Nadja en París, también realizado por el mismo director en 1964, la protagonista experimenta el día a día de la ciudad que la acoge como estudiante para llevar a cabo su tesis sobre el autor francés Marcel Proust. Su papel de visitante la convierte en una observadora de costumbres metropolitanas, y a modo de antropóloga social expone una narración como si se tratara de un diario personal en el que describe lo que observa de los ambientes parisinos, sus barrios, las visitas a espectáculos como teatros, cines o bibliotecas. Mira a la gente respecto a sus hábitos y formas de comportarse. Dicha observación ajena convierte, no obstante, a la narradora en una focalizadora en la que ella misma se ve integrada. Utiliza la ciudad como un espacio practicado ya que, según expone en su monólogo como narradora, dichas experiencias percibidas del espacio transitado perfilarán parte de su personalidad en el trayecto de su vida. 
En el caso del cineasta François Truffaut la experiencia del flânerie queda ejemplificada en su película Jules et Jim, realizada en 1962, y en la que se observan las vivencias de un trío de personajes deambulando por las calles de París, una forma de recorrido que conecta con la alegría de vivir, de la jovialidad, del desenfreno y de la pasión por la despreocupación y la bohemia. Quizá una de las secuencias más significativas que ha pasado a la historia del cine es el largo recorrido, dispuesto desde una panorámica, en la que se observa como los tres protagonistas cruzan el museo del Louvre corriendo, en este caso existe una experiencia basada en romper los moldes éticos que acontece en el espacio museístico. Si el museo del siglo XX es un lugar donde el silencio, la armonía y la vigilancia están destinados al goce de las obras artísticas por los visitantes, y el ámbito que representa supone un aura de espacio cercano a lo sagrado o confeccionado para su admiración, los personajes fragmentan esta misión. No obstante la experiencia de correr en un museo y ver cómo son percibidos por el resto de los visitantes al acecho de que los vigilantes puedan llamarles la atención supone un riesgo que tiene como objetivo la aventura de fragmentar las normas sociales y adoptar un nuevo modo de ver que entronca con la situación social que años más tarde tendrá lugar en los altercado de mayo del 68.

Una última cala en esta muestra de esta generación a través de la ejemplificación de algunos de los directores más significativos de la nouvelle vague recala en la trayectoria de la directora Agnès Varda. En sus películas y documentales queda manifestado el interés por la sociedad que le rodea. Ya desde su primer filme rodado en 1954, titulado La Pointe Courte, muestra desde un punto de vista dramático la vida de una pareja y su relación con el pequeño barrio de pescadores en el que habitan, recogiéndose una visión antropológica de los acontecimientos muy similar a cómo quedaban descritas diversas novelas costumbristas decimonónicas. La mayor parte de sus obras esbozan ejercicios donde sus protagonistas experimentan el espacio, un espacio que se torna dramático, que marca la trayectoria de sus aconteceres y que refleja la focalización del realismo social, del testimonio del paso del tiempo y de una visión histórica próxima al modelo de cine documental. Un cine, a su vez, muy posicionado desde una condición de mirada fotográfica, otra de sus vertientes que desemboca en la denominada escuela humanista en su retrato del ser humano frente a la sociedad que le rodea. 
Otros directores de este período también exploran su visión del flâneur desde una óptica contemporánea donde la calle y la ciudad generan síntomas y conflictos sentimentales entre los personajes. Autores como Chabrol, Malle, Rivette o Eustache exploran en numerosas películas las relaciones sociales de sus protagonistas con el entorno, ámbitos que en ocasiones adoptan una visión agorafóbica que desemboca en la pulsión psicológica escenificada a través de conflictos personales.

\section{Conclusiones.}

A raíz de los ejercicios de microanálisis fílmicos expuestos anteriormente se puede llegar a la conclusión de que la visión del flâneur en el cine supone tres tipos de percepciones ante los modos de representar la realidad circundante de la ciudad: la que adquiere el realizador, la que adquiere determinado personaje y la que adquiere el receptor. Ante este tipo de prácticas surge una visión que determina un sentido pragmático de las acciones.

El paseo, en tanto que recepción estética, se convierte en una narrativa puesto que la interacción del espacio con el individuo denota una relación personal que adquiere un determinado significado contextual ante la acción específica de transitar la ciudad. La psicología del individuo frente a su espacio de convivencia cotidiana retorna en una reflexión personal, a veces, de corte existencialista. La interrogación ante las prácticas de vida cotidiana o lo que supone determinado edificio, espacio o monumento conlleva una historia personal, una experiencia que puede convertirse en sentido de relato, y un posicionamiento del receptor de la mirada.

Los espacios urbanos recorridos pueden transformarse por la mirada cambiando o perdiendo su identidad funcional por cierta identidad particular. Determinados elementos dejan de poseer un registro designado pasando a cumplir otra función diferente (por ejemplo un banco utilizado para sentarse puede dejar de cumplir tal función y ser un objeto que transmite una experiencia estética ante un recuerdo personal). Existe, en este sentido, un intercambio simbólico y semiótico por la capacidad de manifestarse cualidades significativas ante la experiencia de los objetos cotidianos. La ciudad puede leerse como un texto global en el que cada experiencia aparece reflejada por diferentes discursos. 
A su vez, la ciudad, además de considerarse como un registro de citas, hibridaciones y bricolajes de culturas y estilos, adquiere una visión particular que es determinada por el uso de focalizaciones. El punto de vista utilizado es el que adquiere el sentido a lo contemplado.

Finalmente, es necesario incidir que este estudio es simplemente un breve esbozo de lo que supone la reflexión del paseante en algunas de las representaciones cinematográficas de diferentes épocas y etapas de la historia cinematográfica, y que antecede a un campo abierto de futuras investigaciones en las que debe registrarse minuciosamente la evolución de la experiencia de observar el tránsito de las ciudades tanto por los realizadores como por los personajes que adquieren la condición de flâneur en los relatos.

El análisis de los motivos visuales, que ofrecen nuevos modos de ver en las percepciones de un pasado cercano o lejano, consagra diversas fases de la recepción estética como experiencia de la modernidad fílmica Por otro lado, también es necesario citar que existen otras visiones teóricas planteadas por los estudios visuales contemporáneos que ofrecen mayores contribuciones al sentido de la observación y que permiten ampliar el campo de estudio del fenómeno analizado. Es el caso de diversas obras de Martin Jay, Jonathan Crary o Michel de Certeau, entre otros. Sus aportaciones, no obstante, servirán para dotar de nuevas investigaciones tanto al objeto de estudio como a los problemas de percepción visual y a las transformaciones de regímenes escópicos.

\section{Bibliografía.}

BAUDElAIRE, Charles (1999): “El pintor en la vida moderna”, en V.V.A.A. Salones y otros escritos sobre arte. Visor / La balsa de la medusa. Madrid

BENJAMIN, Walter (2005): El libro de los pasajes. Akal. Madrid.

BUCK-MORSS, Susan (1995): Dialéctica de la mirada. Walter Benjamin y el proyecto de los Pasajes. Visor / La balsa de la medusa. Madrid.

CHARNEY, Leo y SCHWARTZ, Vanessa R. [ed.] (1995): Cinema and the Invention of Modern Life. University of California. USA.

De BAECQUe, Antoni (2003). La política de los autores. Una cinefilia a contracorriente. Paidós. Barcelona. 
DelgAdO, Manuel (2006): Sociedades movedizas. Anagrama. Barcelona.

DuQue, Félix (ed.) (2009): Poe. La mala conciencia de la modernidad. Círculo de Bellas Artes. Madrid.

FrISBY, David (1992): Pasajes urbanos de la modernidad. Buenos Aires: Universidad Nacional de Quilmes.

FRISBY, David (2007): Fragmentos de la modernidad. Teorías de la modernidad en la obra de Simmel, Kracauer y Benjamin. Visor / La balsa de la medusa. Madrid.

FÜZESSERY, Stéphane y SIMAY, Philippe [dir.] (2008): Le choc des metropoles. Simmel, Kracauer, Benjamin. Editions de l'éclat. Paris.

GunNing, Tom (1989): “The Cinema of Atraction: Early Film, Its Spectator and the Avant Garde" en ElSAESSER, Thomas y BARKER, Adam (eds.). Early Film. British Film Institute. London.

HUART, Louis (2018): Fisiología del flâneur. Gallo Nero Ediciones. Madrid.

POE, Edgard (2008): “El hombre en la multitud" en Cuentos completos. Augur Libros. Madrid.

RocHA, Servando (2019): "Pío Baroja y el fin del mundo" en Baroja, Pío. Las calles siniestras. Antología del eterno paseante. La Felguera. Madrid.

SCHAEFFER, Jean-Marie (2018): La experiencia estética. La marca editora. Buenos Aires.

ThOreaU, David (2006): Pasear. Olañeta. Palma de Mallorca.

V.V.A.A. (2004). La nouvelle vague. Sus protagonistas. Paidós. Barcelona.

ZunZuneGuI, Santos (1996): La mirada cercana. Microanálisis fílmico. Paidós. Barcelona. 